\title{
二维过渡金属硫族化合物在生物医学中的应用
}

\author{
刘腾程亮刘庄* \\ (苏州大学功能纳米与软物质研究院 苏州大学纳米协同创新中心 江苏省碳基功能重点实验室 苏州 215123)
}

\begin{abstract}
摘要 二维过渡金属硫族化合物(TMDs) 是继石墨烯纳米材料发展之后一类新型的二维纳米材料. 由于其特殊的物理 化学性质, TMDs 二维纳米材料在能源、光电器件、催化反应等多个领域引起了人们广泛的研究兴趣. 近年来这类材料 在纳米生物医学方面也得到人们广泛的关注. 这篇综述简单介绍 TMDs 二维层状纳米材料的制备、表面修饰、生物成 像、肿瘤治疗和毒理学研究, 并对二维 TMDs 纳米材料未来在生物医学领域的发展做出展望.
\end{abstract}

关键词 二维纳米材料; 过渡金属硫族化合物; 制备; 修饰; 生物成像; 肿瘤治疗; 生物安全性

\section{Two Dimensional Transitional Metal Dichalcogenides for Biomedical Applications}

\author{
Liu, Teng Cheng, Liang Liu, Zhuang* \\ (Institute of Functional Nano \& Soft Materials (FUNSOM), Collaborative Innovation Center of Suzhou Nano Science and \\ Technology, the Jiangsu Key Laboratory for Carbon-Based Functional Materials \& Devices, Soochow University, \\ Suzhou 215123)
}

\begin{abstract}
Transitional metal dichalcogenides (TMDs) nanosheets are a new kind of two-dimensional nanomaterials emerging after graphene. Due to their intriguing physical and chemical properties, TMD nanosheets have attracted wide interests in many different fields in the past several years. Recently, many groups have also started to explore their biomedical applications. This review article summarizes the synthesis, surface modification, biomedical applications, as well as biosafety evaluation of TMDs nanosheets, and discusses future perspectives of applying this new type of two-dimensional nanomaterials in the area of biomedicine.

Keywords two-dimensional nanomaterials; transitional metal dichalcogenides; synthesis; modification; biomedical imaging; cancer therapy; biosafety
\end{abstract}

\section{1 引言}

二维纳米材料在两个维度上的原子排布和键作用 力相似并远远强于第三个维度. 由于极薄的厚度和二维 的结构, 二维纳米材料具备许多奇特而有用的性质诸如 极大的比表面积, 丰富的化学反应位点, 特殊的光电特 性等等 ${ }^{[1]}$. 石墨烯是最为经典的二维纳米材料 ${ }^{[2]}$. 自 2004 年发现至今, 石墨烯二维纳米材料在光电器件、能 源、催化、生物医用等诸多领域得到了广泛的应用 ${ }^{[3]}$. 然 而, 石墨烯纳米材料仅仅由碳原子构成, 组分和性质相 对简单且难以调制, 所以亟需更多种类的二维纳米材料 来添砖加瓦 ${ }^{[4]}$.

过渡金属硫族化合物(TMDs) 的结构类似于石墨， 每一层由过渡金属和硫族元素以三明治的结构共价结 合, 而层与层之间则通过弱的范德华力连接, 因此很容 易破坏层与层之间的弱作用力来制备得二维的 TMDs 层状纳米材料 ${ }^{[5]}$. 基于这样的结构特点, TMDs 二维纳米
材料拥有许多特殊的光电物理性质, 在场效应转换 器 ${ }^{[6]}$ 、锂离子电池 ${ }^{[7]}$ 、集成电路 ${ }^{[8]}$ 、气体检测 ${ }^{[9]}$ 、氢气制 备 ${ }^{[10]}$ 、光电转化器 ${ }^{[1]}$ 和催化反应 ${ }^{[12]}$ 等领域得到了广泛的 应用. 由于其极大的比表面积, 较高的近红外区吸收, 以及原子序数大等特点, 最近 TMDs 二维纳米材料在生 物医学方面得到了快速的发展 ${ }^{[13]}$. 这篇综述简单介绍 了二维 TMDs 纳米材料在生物医学领域的最新研究进 展, 主要集中在 TMDs 二维纳米材料的合成与表面修 饰，在生物检测、生物成像、肿瘤治疗等方面的生物医 学应用以及毒理学的初步研究.

\section{TMDs 二维纳米材料的制备与表面修饰}

\section{1 制备方法}

可靠的制备方法是研究二维 TMDs 纳米材料性质 并加以应用的第一步. 二维 TMDs 纳米材料的合成方法 主要分为自上而下(top-down)、自下而上(bottom-up)两

*E-mail: zliu@suda.edu.cn

Received April 26, 2015; published June 26, 2015.

Project supported by the National Natural Science Foundation of China (Nos. 51302180, 51222203, 51002100, 51132006) and the 973 Program (Nos. 2011CB911002, 2012CB932601).

项目受国家自然科学基金(Nos. 51302180, 51222203, 51002100, 51132006)和国家 973 计划(Nos. 2011CB911002, 2012CB932601)资助. 
种(图 1). 自上而下的合成方法是基于 TMDs 的层与层 之间弱的相互作用力, 一般包括机械剥离法 ${ }^{[11 a, 14]}$ 、溶剂 超声法 ${ }^{[15]}$ 、锂离子插层剥离法 ${ }^{[16]}$ 、电化学插层剥离法 ${ }^{[17]}$ 等. 而自下而上的方法主要有气相热沉积 ${ }^{[18]}$, 溶剂热 法 $^{[19]}$ 和高温液相法 ${ }^{[20]}$ 等, 比较容易通过调节反应条件 来控制材料的组织形貌和尺寸大小.

\subsection{1自上而下}

由于 TMDs 结构中层与层之间弱的范德华力, 我们 可以通过物理方法直接从块状材料上将单层的纳米片 剥离出来. 最原始的是机械剥离法(微机械力, 透明胶 带法, 研磨), 曾用于制备石墨烯, 最近 Geim 等用这种
方法也制备得到了单层的 $\mathrm{NbSe}_{2}, \mathrm{BN}, \mathrm{MoS}_{2}, \mathrm{WS}_{2}$

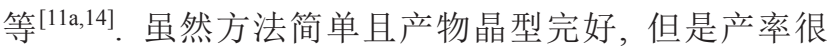
低，只能用于对材料基础性质的研究.

Coleman 等 ${ }^{[15 b]}$ 发现，当溶剂的表面能与二维 TMDs 纳米材料相符时, 纳米片层更分散稳定. 根据这一现象, 许多课题组通过调控混合溶剂的比例制备了 $\mathrm{WS}_{2}$, $\mathrm{MoS}_{2}, \mathrm{MoSe}_{2}, \mathrm{MoTe}_{2}, \mathrm{BN}$ 等多种二维纳米材料(图 $1 \mathrm{a})^{[15]}$. 这种方法的产率较第一种有所提高, 但依旧不 足以进行大量的应用，而且制得的材料分散在有机溶剂 中, 不能直接用于生物医学. a

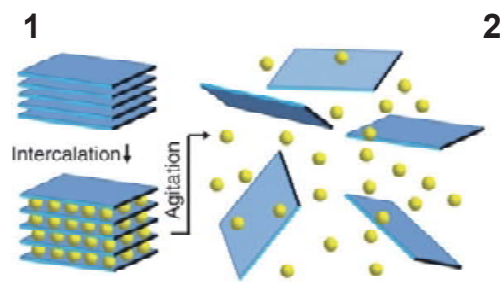

3

2

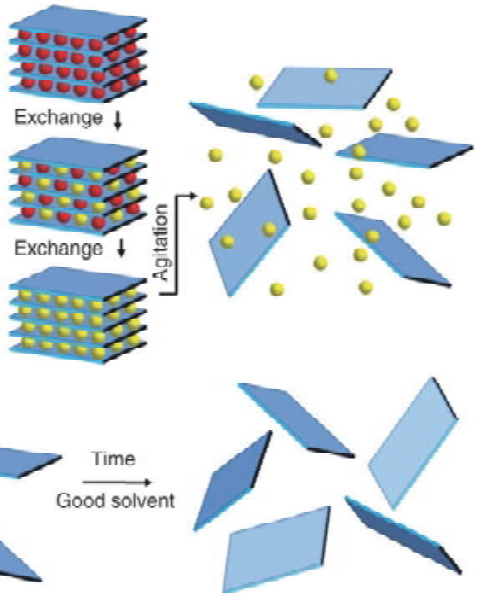

b

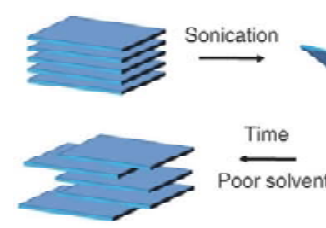

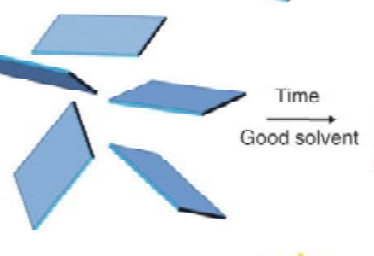
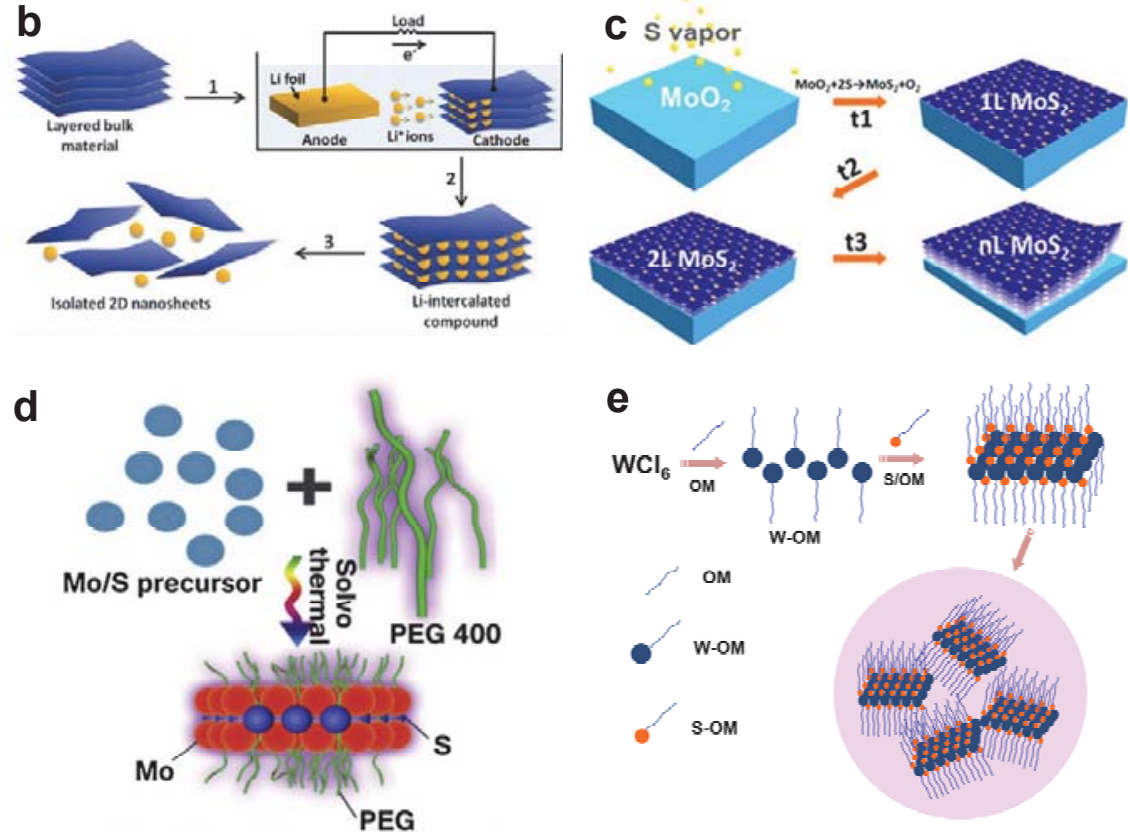

图 1 (a) 主要的液相剥离法(1. 离子插层, 2. 离子交换, 3. 超声辅助剥离)的示意图. (b)电化学锂离子插层法从块状材料来制备二维纳米片. (c)化 学气相沉积法制备并剥离 $\mathrm{MoS}_{2}$ 的示意图. (d)溶剂热反应制备 $\mathrm{MoS}_{2}-\mathrm{PEG}$. (e)高温液相法制备超薄 $\mathrm{WS}_{2}$ 纳米片

Figure 1 (a) Schematic description of the main liquid exfoliation mechanisms (1. Ion intercalation, 2. Ion exchange, 3. Sonication assisted exfoliation). Reprinted with permission from ref. [15d]. Copyright 2013 Science. (b) Electrochemical lithiation process for the fabrication of 2D nanosheets from the layered bulk material. Reprinted with permission from ref. [17b]. Copyright 2011 Wiley-VCH. (c) Schematics for the synthesis and cleavage of $\mathrm{MoS}_{2}$ by CVD. Reprinted with permission from ref. [18d]. Copyright 2013 American Chemical Society. (d) Schematic illustration of the solvothermal synthesis procedure of $\mathrm{MoS}_{2}$-PEG nanosheets. Reprinted with permission from ref. [19a]. Copyright 2014 Elsevier Ltd. (e) Synthesis of ultrathin $\mathrm{WS}_{2}$ nanoflakes by a hydrothermal method. Reprinted with permission from ref. [20b]. Copyright 2014 Wiley-VCH 
Morrison ${ }^{[16]}$ 提出的锂离子插层剥离法是在有机溶剂 中将 TMDs 粉末与正丁基锂混合来进行插层, 随后在水 中反应超声而剥离的简单易行的合成方法. 新加坡南洋 理工大学张华教授课题组 ${ }^{[17]}$ 通过电化学方法(图 1b), 进 一步优化了这种化学插层方法, 实现了可控的锂离子插 层, 使得 TMDs 合成更简单高效. 这种化学剥离法通过 介入在 TMDs 层与层之间锂离子与之后加入的去离子 水进行反应, 产生大量的氢气将 TMDs 层推开, 伴随着 剧烈的超声, 使得微弱的层间作用力逐渐断裂, 得到单 层或者多层的纳米材料. 强烈的超声会破坏晶型, 在表 面形成大量缺陷, 活性位点增多, 但对其光电性质有一 定的影响. 这一方法因产物能直接溶于水, 具有一定的 稳定性且易于修饰而适于生物医学领域

\subsection{2 自下而上}

化学气相沉积法通过不同化合物在反应室的空间 气相反应, 可以在基底上大量制备大面积的 TMDs 二维

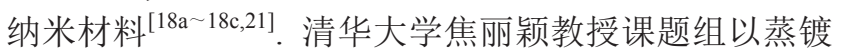
硫化 $\mathrm{MoO}_{2}$ 微晶制备了高度结晶的超薄 $\mathrm{MoS}_{2}$ 二维纳米 材料(图 1c) ${ }^{[18 \mathrm{~d}]}$. 北京大学的刘忠范教授等 ${ }^{[18 \mathrm{e}]}$ 则用低压 气相沉积法大量制备了 $\mathrm{WS}_{2}$ 纳米片. 刻蚀基底得到的 TMDs 二维纳米材料可以用于构建光电器件, 但这种尺 寸较大且不溶于水的纳米片不适用于生物医学领域.

为了得到水溶性较好的小尺寸 TMDs 二维纳米材 料, 许多课题组开始研究溶剂热和高温液相的方法. 中 科院硅酸盐所施剑林教授课题组则首次通过溶剂热反 应, 以 $\left(\mathrm{NH}_{4}\right)_{2} \mathrm{MoS}_{4}$ 为前驱体, 一步合成了大小可控的, 聚乙二醇直接修饰了的 $\mathrm{MoS}_{2}$ 纳米薄片 (图 1d $)^{[19 a]}$. 中国 科学技术大学杨晴教授课题组 ${ }^{[19 b]}$ 则用三苯基铋和二茮 基二硫在乙醇中通过溶剂热反应合成了厚度为 $2.2 \mathrm{~nm}$ 的超薄 $\mathrm{Bi}_{2} \mathrm{~S}_{3}$ 纳米片. 最近, 施剑林课题组 ${ }^{[19 \mathrm{c}]}$ 又用类似 的方法用 $\left(\mathrm{NH}_{4}\right)_{2} \mathrm{MoS}_{4}$ 和 $\mathrm{Bi}\left(\mathrm{NO}_{3}\right)_{3} \cdot 5 \mathrm{H}_{2} \mathrm{O}$ 为原料一步法制 备了二维 $\mathrm{MoS}_{2} / \mathrm{Bi}_{2} \mathrm{~S}_{3}$ 复合材料.

Jeong 课题组 ${ }^{[20 \mathrm{a}]}$ 则用简单快速的高温液相法, 以 $\mathrm{Na}_{2} \mathrm{SeO}_{3}$ 和 $\mathrm{Bi}\left(\mathrm{NO}_{3}\right)_{3} \cdot 5 \mathrm{H}_{2} \mathrm{O}$ 制备了超薄 $(4 \sim 6 \mathrm{~nm})$ 的 $\mathrm{Bi}_{2} \mathrm{Se}_{3}$ 纳米盘, 通过调节温度来调节纳米片的形貌, 还 可以用阳离子高分子表面活性剂在控制厚度不变的情 况下增大纳米片层的尺寸. 而最近, 我们课题组运用高 温液相法, 通过过渡金属 $(\mathrm{M})$ 氯化物和油胺 $(\mathrm{OM})$ 形成的 M-OM 配体, 与之后加入的硫粉在高温下快速反应来制 备 TMDs 二维纳米材料. 这种合成方法可以得到不同种 类的, 大小比较均匀的二维 TMDs 纳米材料, 如 $\mathrm{WS}_{2}{ }^{[20 \mathrm{~b}]}$ (图 1e), $\mathrm{TiS}_{2}$ 等 ${ }^{[20 \mathrm{c}]}$, 我们还可以掺杂不同元 素 ${ }^{[20 \mathrm{~d}]}$ 来优化纳米材料的性质与功能. 这类高温液相法 可以通过改变反应条件来调节材料的尺寸形貌和元素 组成等, 但由于不同元素有不同的反应活性, 我们现在 能合成的二维 TMDs 种类仍然有限.

\section{2 表面修饰}

\subsection{1 颈基小分子/聚乙二醇}

Dravid 课题组提出, 经锂离子插层剥离法获得的二 维 TMDs 纳米材料表面由于硫原子的缺失形成了大量 的缺陷，而这些缺陷很容易和末端为颈基的分子结合. 他们测试了几种带颈基的分子对二维 $\mathrm{MoS}_{2}$ 纳米材料的 修饰(图 2a), 发现很好的稳定性 ${ }^{[22]}$. 然而, 这种小分子 修饰的材料注射到体内后会形成团聚而被巨噬细胞吞 噬清除. 因此, 我们用硫辛酸与氨基聚乙二醇反应, 得 到末端有双硫键的高分子(LA-PEG)来高效地修饰单层 $\mathrm{WS}_{2}{ }^{[23]} 、 \mathrm{MoS}_{2}{ }^{[24]}$ 二维纳米材料(图 2b), 使其在生理溶液 中具有很好的稳定性和生物相容性. 通过原子力显微镜 表征(图 2c 2e), 我们发现经过 LA-PEG 的修饰, $\mathrm{MoS}_{2}$ 纳米片的厚度稍有增加, 而尺寸从平均 $120 \mathrm{~nm}$ 减小至 $50 \mathrm{~nm}$.

\subsection{2 双亲性聚乙二醇}

由于高温液相法制得的 TMDs 纳米片表面带有疏 水的油胺分子, 我们可以用双亲性高分子如 $\mathrm{C}_{18} \mathrm{PMH}-\mathrm{PEG}$ 通过疏水作用力与之结合来进行表面修 饰. 我们发现修饰好的 $\mathrm{TiS}_{2}$ 二维纳米材料在生理溶液中 具有很好的稳定性, 在细胞水平和小鼠体内没有发现明 显的毒性, 因此具有良好的生物相容性 ${ }^{[20 c]}$.

\section{2 .3 其他方法}

Yuan 等 ${ }^{[25]}$ 在超声过程中加入聚丙烯酸, 通过羧基 和铇原子的螯合使 $\mathrm{WS}_{2}$ 纳米片有更好的分散性，但这种 修饰还不适用于生物体内. 国家纳米科学中心赵宇亮课 题组 ${ }^{[26]}$ 则通过壳聚糖修饰了发烟硫酸剥离的 $\mathrm{MoS}_{2}$ 纳米 片，使其表面带有极高的正电荷，在生理溶液中获得了 很好的长期稳定性. 类似地, 牛血清蛋白吸附到 $\mathrm{WS}_{2}$ 纳 米片表面也可以增强它们在生理溶液中的稳定性 ${ }^{[27]}$.

\section{$3 \mathrm{TMDs}$ 二维纳米材料在生物医学中的应用}

\section{1 生物检测}

医学诊断、药物发现、环境监测和食品安全等诸多 领域都需要生物分子检测，因此亟需发展简单、灵敏、 选择性高且便宜的生物探针. 与石墨烯纳米材料类似, TMDs 二维纳米材料具有较大的比表面积, 可以通过物 理作用吸附大量的芳香族共轭分子. 同时 TMDs 二维纳 米材料在近红外区具有强的光学吸收, 能淬灭很多带有 菼光基团的物质.

新加坡南洋理工大学张华教授课题组 ${ }^{[28]}$ 首次将单 层 $\mathrm{MoS}_{2}$ 纳米片作为纳米探针, 在均相溶液中实现了简 单高效、快速灵敏的分子检测(图 3). 他们的研究发现 $\mathrm{MoS}_{2}$ 纳米片对单链 DNA 和双链 DNA 不同的亲和性与 苂光淬灭效果, 即 $\mathrm{MoS}_{2}$ 纳米片可以通过范德华力吸附 染料标记的单链 DNA 并淬灭掉染料的苂光; 而当单链 
a

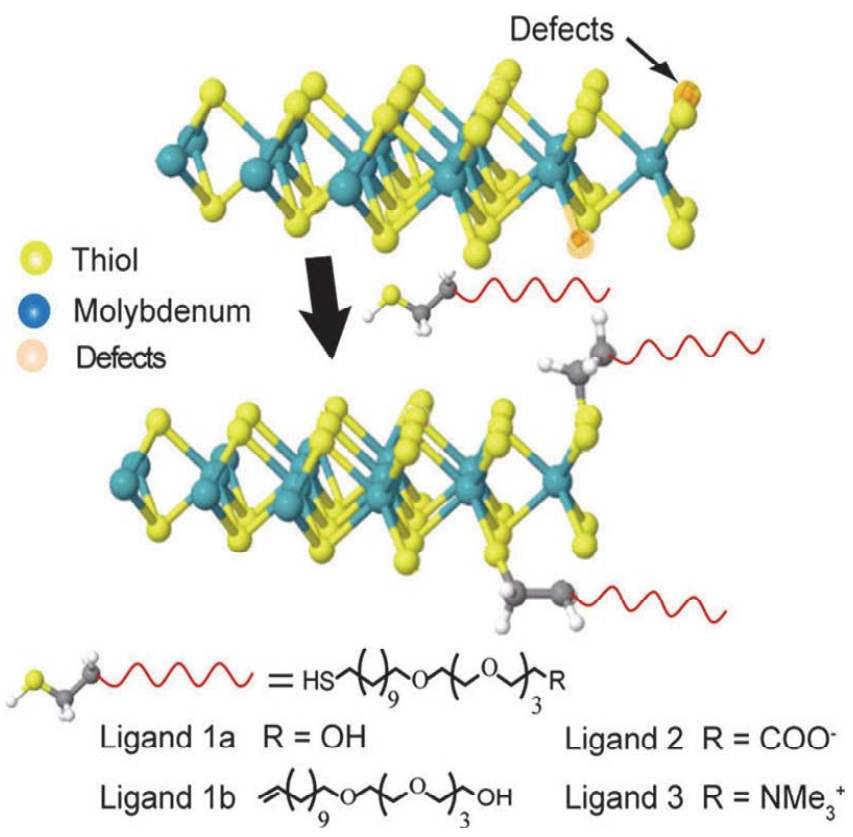

b

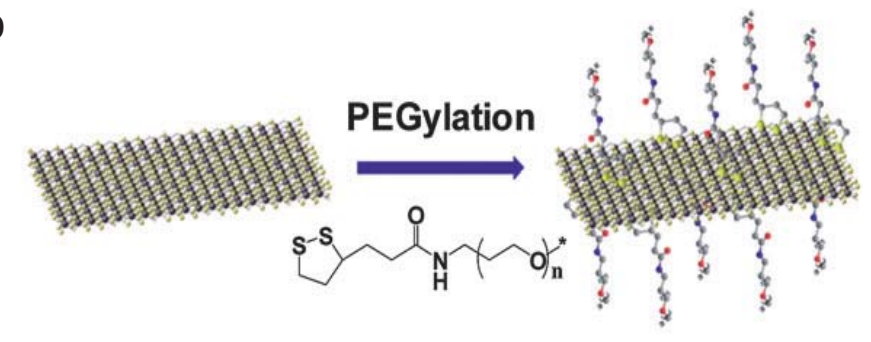

C
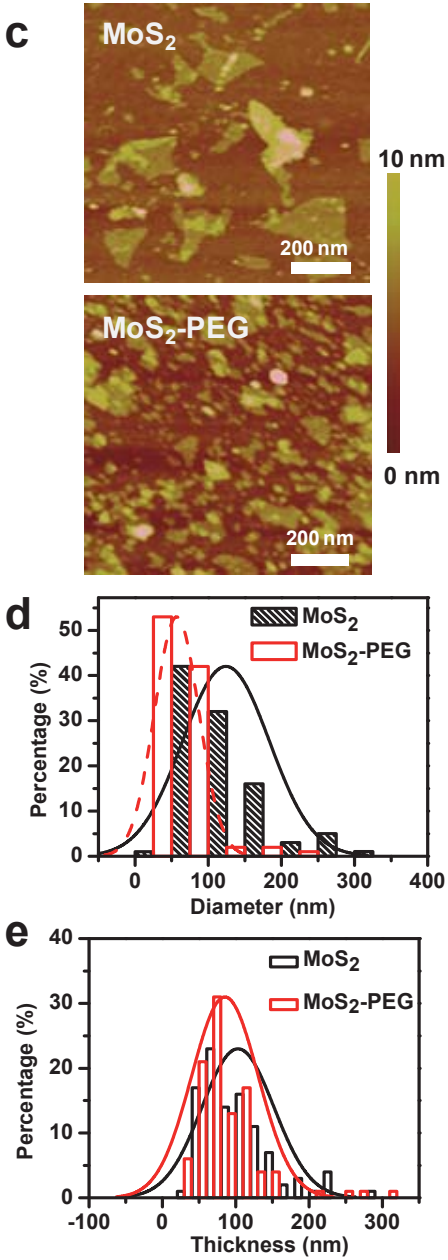

图 2 (a)化学剥离法制得的 $\mathrm{MoS}_{2}$ 纳米片与配体结合的结构模型示意图. (b)用 LA-PEG 修饰 $\mathrm{MoS}_{2}$ 纳米片的示意图. (c) $\mathrm{MoS}_{2}$ 纳米片在聚乙二醇修 饰前后的原子力显微镜图. (d, e) 原子力显微镜测得的 $\mathrm{MoS}_{2}$ 和 $\mathrm{MoS}_{2}-\mathrm{PEG}$ 的尺寸(d)与高度(e)分布图

Figure 2 (a) Structural models illustrating ligand conjugation of ce- $\mathrm{MoS}_{2}$ sheets. Reprinted with permission from ref. [22]. Copyright 2013 American Chemical Society. (b) A scheme showing the surface modification of $\mathrm{MoS}_{2}$ by LA-PEG. Reprinted with permission from ref [24b]. Copyright 2014 The Royal Society of Chemistry. (c) AFM images of $\mathrm{MoS}_{2}$ before and after PEGylation. (d, e) AFM measured diameter (d) and thickness (e) distributions of $\mathrm{MoS}_{2}$ and $\mathrm{MoS}_{2}$-PEG. Reprinted with permission from ref. [24a]. Copyright 2014 Wiley-VCH

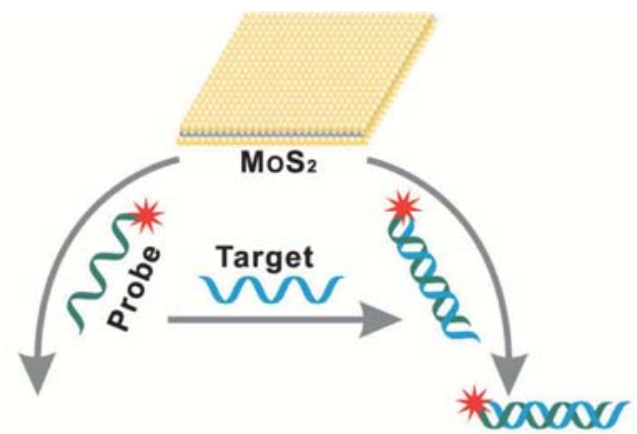

$$
\text { d } 2
$$

图 3 二维 $\mathrm{MoS}_{2}$ 纳米片检测苂光 DNA.

Figure 3 Schematic Illustration of the Fluorimetric DNA Assay. Reprinted with permission from ref. [28]. Copyright 2013 American Chemical Society.
DNA 与其互补链结合形成双链 DNA 后，其紧密的螺旋 结构完全屏蔽了核酸碱基与单层 $\mathrm{MoS}_{2}$ 纳米片的作用, 而荧光也会恢复. 基于这一原理, 他们将 $\mathrm{MoS}_{2}$ 纳米片 层材料应用于检测 DNA 和小分子，通过荧光强度的高 低来定量检测目标分子的浓度. 这种混合-检测分析方 法非常简单，灵敏度极高(500 pM DNA)，并且能快速完 成原位检测。

$\mathrm{Ou}$ 等 ${ }^{[29]}$ 利用 $\mathrm{MoS}_{2}$ 二维纳米材料本身固有的苂光 性质来检测酶促反应过程中的离子交换, 并实现了对死 细胞核活细胞中离子交换的监测. 而 Sarkar 等 ${ }^{[30]}$ 则将二 维 $\mathrm{MoS}_{2}$ 片层作为通道材料构建了以场效应管为基础的 生物探针，用于检测 $\mathrm{pH}$ 值和生物分子. 此外, Yuan, Jiang 等 ${ }^{[2,31]}$ 的工作表明, $\mathrm{WS}_{2}$ 纳米片也可以作为纳米生 物探针. 


\section{2 生物成像}

\section{2 .1 光声成像}

二维纳米材料由于其特殊的物理化学性质, 在生物 医学中具有广泛的应用前景. 光声成像是利用有光吸收 的组织或者显影剂, 将脉冲激光转化成热能, 引起热膨 胀而产生超声, 并通过检测这种超声信号来重构图像的 一种新兴医学成像方法 ${ }^{[32]}$. 与传统的光学成像模式相 比, 这种光进声出的成像法大大提高了空间分辨率和组 织穿透性. 为了提高成像质量, 光声成像需要在近红外 区有较高吸收的造影剂, 而 TMDs 二维层状纳米材料在 整个近红外区都具有较高的光学吸收, 是一种非常理想
的光声显影剂.

我们利用锂离子插层制备得到的单层 $\mathrm{WS}_{2}$ 纳米薄 片, 并且通过 PEG 表面修饰使其具有很好的水溶性和 生物相容性. 尾静脉注射到小鼠体内后, 我们都能在脉 冲激光照射下清楚地观察到肿瘤区域的信号明显增强, 而在对照组中则只能看到主要的血管, 这表明 PEG 修 饰后的 $\mathrm{WS}_{2}$ 二维纳米材料会通过增强的渗透和滞留 (EPR)效应在肿瘤部位进行富集. 同样，通过瘤内注射 的方式也能明显观察到肿瘤区域的信号增强(图 4e $)^{[23]}$. 其他 TMDs 二维纳米材料如 $\mathrm{MoS}_{2}{ }^{[24 b]}, \mathrm{TiS}_{2}{ }^{[20 c]}$, 同样也 具有很好的光声成像效果. (a)

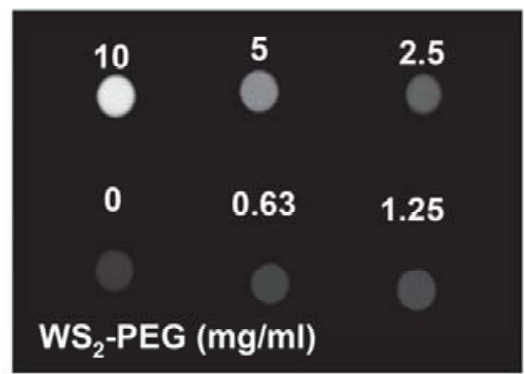

(c)

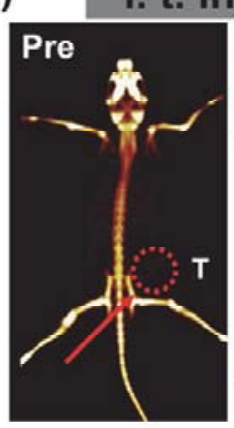

i. t. injection

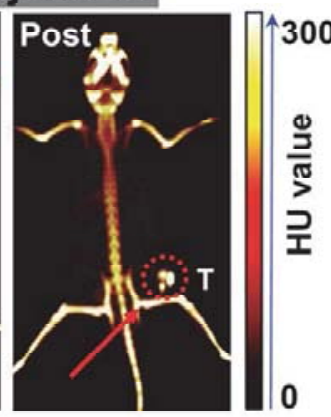

(b)

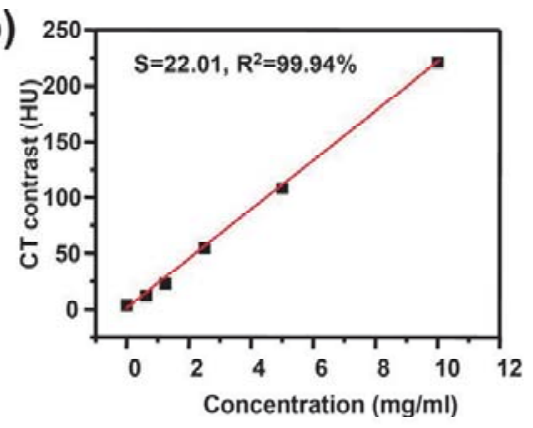

(d)

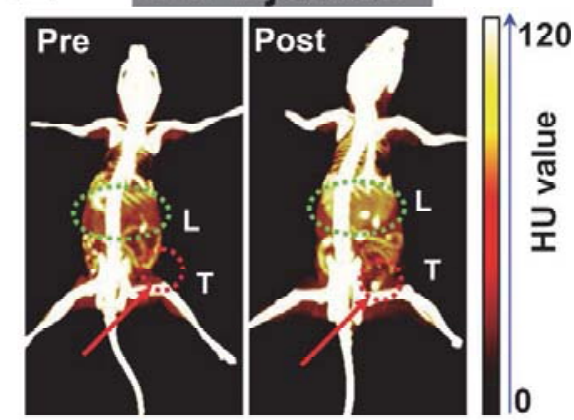

(e)
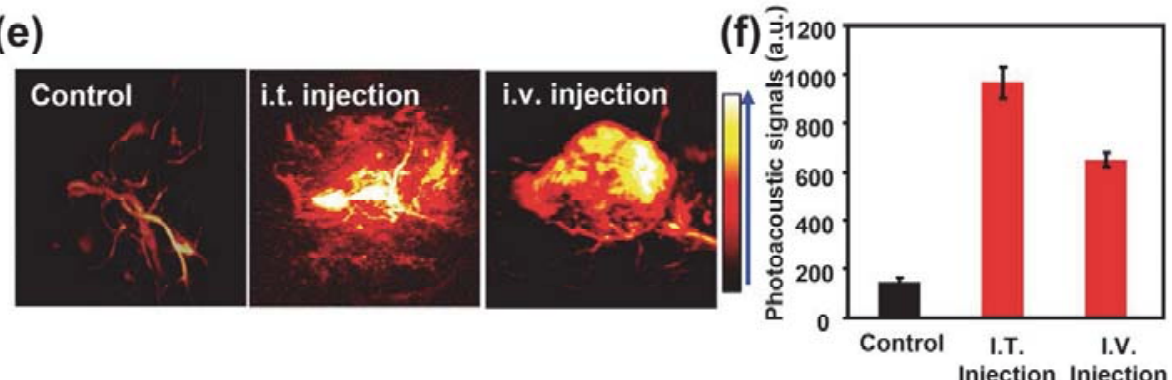

图 4 4 1 1 肿瘤小鼠模型上的活体双模式成像. (a)不同浓度 $\mathrm{WS}_{2}-\mathrm{PEG}$ 溶液的 CT 图像. (b) $\mathrm{WS}_{2}-\mathrm{PEG}$ 溶液单位浓度的 $\mathrm{HU}$ 值. (c) 瘤内注射 $\mathrm{WS}_{2}-\mathrm{PEG}$ $\left(5 \mathrm{mg} / \mathrm{mL}, 20 \mu \mathrm{L}\right.$ ) 前后小鼠的 CT 成像. (d) 尾静脉注射 $\mathrm{WS}_{2}$-PEG $(5 \mathrm{mg} / \mathrm{mL}, 200 \mu \mathrm{L}$ )前后小鼠的 CT 成像. 小鼠的肝部(绿色虚线圈内)和肿瘤部位 (红色虚线圈内)CT 信号值明显增强. (e)瘤内 $(20 \mu \mathrm{L})$ 或尾静脉 $(200 \mu \mathrm{L})$ 注射 $\mathrm{WS}_{2}$-PEG $(2 \mathrm{mg} / \mathrm{mL})$ 前后小鼠的光声成像. (f) 瘤内 $(20 \mu \mathrm{L})$ 或尾静脉(200 $\mu \mathrm{L})$ 注射 WS2-PEG $(2 \mathrm{mg} / \mathrm{mL})$ 前后小鼠肿瘤部位的光声的量化信号强度。

Figure 4 In vivo dual-model imaging in 4T1-tumor bearing mice. (a) CT images of $\mathrm{WS}_{2}$-PEG solutions with different concentrations. (b) HU values of $\mathrm{WS}_{2}$-PEG as the function of its concentrations. (c) CT images of mice before and after i. t. injection with $\mathrm{WS}_{2}-\mathrm{PEG}(5 \mathrm{mg} / \mathrm{mL}, 20 \mu \mathrm{L})$. (d) CT images of mice before and after i. v. injection with $\mathrm{WS}_{2}$-PEG $(5 \mathrm{mg} / \mathrm{mL}, 200 \mu \mathrm{L})$. The CT contrast was obviously enhanced in the mouse liver (green dashed circle) and tumor (red dashed circle). (e) PAT images of tumors on mice before and after i. t. or i. v. injection with $\mathrm{WS}_{2}$-PEG. (f) Photoacoustic signals in the tumors from mice before and after i. t. or i. v. injections of $\mathrm{WS}_{2}$-PEG solution. For PAT imaging, 20 or $200 \mu \mathrm{L}$ of $\mathrm{WS}_{2}$-PEG at the concentration of 2 $\mathrm{mg} / \mathrm{mL}$ was i. t. or i. v. administrated, respectively. Reprinted with permission from ref. [23]. Copyright $2013 \mathrm{Wiley-VCH.}$ 


\subsubsection{X 射线计算机断层扫描成像}

$\mathrm{X}$ 射线计算机断层扫描成像 $(\mathrm{CT})$ 是根据不同组织对 $\mathrm{X}$ 射线的吸收能力不同, 通过电脑的三维技术重建出断 层面影像的一种临床医学诊断方法, 可以提供很高的空 间分辨率. 原子序数越高的元素对 $\mathrm{X}$ 射线的吸收越强, 因而很多研究表明多种包含高原子序数元素( I, Au, Bi, $\mathrm{Ta}, \mathrm{La})$ 的纳米材料是非常有效的 CT 造影剂. 类似地, 由过渡金属元素组成的二维 TMDs 纳米材料也有希望 成为 $\mathrm{CT}$ 造影剂.

我们最近的工作发现, 由于钨原子较高的原子序数 (W, 74; I, 53), $\mathrm{WS}_{2}$ 二维纳米材料(22.01 HU L/g) 比临床 使用的基于碘的造影剂(15.9 HU L/g)具有更高的 X射线 衰减能力. 将聚乙二醇修饰好的 $\mathrm{WS}_{2}$ 二维纳米材料通过 瘤内或者尾静脉注射入小鼠后, 我们发现肿瘤部位的信 号强度显著提高. 与此同时, 我们发现经尾静脉注射材 料的小鼠在肝部位也有很强的信号值, 表明网状内皮系 统也会大量滞留纳米片层材料(图 4d) ${ }^{[23]}$. 这一工作表明 $\mathrm{WS}_{2}$ 二维纳米材料是非常有效的 CT 造影剂. 赵宇亮课 题组 ${ }^{[27]}$ 将 $\mathrm{BSA}$ 修饰的 $\mathrm{WS}_{2}$ 二维纳米材料瘤内注射到带 有 HeLa 肿瘤的裸鼠体内, 同样也证实了 $\mathrm{WS}_{2}$ 的 CT 成 像效果. 此外, 一些工作表明 $\mathrm{Bi}_{2} \mathrm{Se}_{3}{ }^{[28]}$ 和 $\mathrm{MoS}_{2} / \mathrm{Bi}_{2} \mathrm{~S}_{3}$ 纳 米片 ${ }^{[19 \mathrm{c}]}$ 也有很强的 $\mathrm{X}$ 射线衰减能力, 可以用于活体的 肿瘤组织 $\mathrm{CT}$ 成像.

\section{2 .3 多模式成像}

一些二维过渡金属纳米材料本身具有光声和 CT 双 模式成像, 但为了赋予 TMDs 二维纳米材料更丰富的成 像功能, 我们需要将其与其他功能纳米材料进行复合. 我们通过巧妙的设计, 将用二颈基丁二酸修饰的四氧化 三铁纳米颗粒(IO)通过颈基作用自组装到 $\mathrm{MoS}_{2}$ 二维片 层上, 形成了 $\mathrm{MoS}_{2}-\mathrm{IO}$ 复合材料 ${ }^{[33]}$. 我们先使用 LA-PEG 上的双硫键和 $\mathrm{MoS}_{2}$ 二维片层上的缺陷之间的 作用来对该纳米复合材料进行修饰, 在生理溶液中获得 了较好的稳定性. 但是由于 $\mathrm{MoS}_{2}$ 二维片层上一部分缺 陷已经被 IO 占据, PEG 修饰的效果会略有降低. 此外, 生物体内丰富的谷胱甘肽也会降低 $\mathrm{MoS}_{2}-\mathrm{IO}$ 的稳定性. 因此, 我们又通过六氨基聚乙二醇上的氨基与 IO 上的 羧基作用来进行下一步修饰, 显著提高了该纳米复合材 料 $\left(\mathrm{MoS}_{2}-\mathrm{IO}-(\mathrm{d}) \mathrm{PEG}\right)$ 的生物相容性. 有趣的是, ${ }^{64} \mathrm{Cu}$, 一 种常用的正电子发射放射性同位素, 无需螯合剂就能牢 牢地吸附在 $\mathrm{MoS}_{2}$ 二维片层上, 从而可以用作正电子放 射断层成像(PET)的造影剂. 另一方面, $\mathrm{MoS}_{2}$-IO-(d)PEG 拥有很强的近红外区吸收和超顺磁性, 因此可用于光声 成像和核磁成像. PET 成像具有很高的灵敏度并能在体 内量化追踪正电子发射放射性同位素, 光声成像能根据 材料在肿瘤里的分布清晰地展示出肿瘤形貌, 而核磁成 像则对软组织有很好的显影效果. 这个以二维 $\mathrm{MoS}_{2}$ 片 层材料为基础, 构建的三模式成像多功能纳米材料可以 提供可靠全面的生物学信息(图 5).

\section{4 肿瘤治疗}

\section{1 光热治疗}

光热治疗是利用有较强光吸收的光热试剂将光能 转换成热能, 通过产生的高温消除癌细胞的一种治疗手 段, 有很好的区域选择性和较低的副作用. 由于生物组 织在近红外区(NIR)是透明的, 在 NIR 有很强吸收的二 维 TMDs 纳米材料是非常好的光热试剂. Dravid 课题 组 ${ }^{[34]}$ 首次在细胞水平展示了二维 $\mathrm{MoS}_{2}$ 纳米片作为近红 外吸收试剂在体外光热治疗癌细胞的能力. 最近我们课 题组利用锂离子插层技术得到二维 $\mathrm{WS}_{2}$ 纳米片, 发现它 们在近红外区也具有很强的光学吸收. 通过尾静脉注射 到小鼠体内, 发现大部分的材料在网状内皮系统会有较 高的滞留(包括肿瘤). 当外加近红外 $808 \mathrm{~nm}$ 激光照射 5 min 后, 肿瘤完全消灭, 并且长时间内没有发生转移和 再生现象, 大大提升了小鼠的存活率. 同样地, 我们也 发现 $\mathrm{MoS}_{2} 、 \mathrm{TiS}_{2}$ 等二维层状纳米材料通过系统注射, 在 活体水平上也具有很好的光热治疗效果. 还有通过局部 肿瘤注射 $\mathrm{Bi}_{2} \mathrm{Se}_{3}{ }^{[28]}$ 和 $\mathrm{MoS}_{2} / \mathrm{Bi}_{2} \mathrm{~S}_{3}{ }^{[19 \mathrm{c}]}$ 二维纳米材料, 证 明了它们在活体小鼠上通过光热消除肿瘤的能力.

\section{2 联合治疗}

\section{2 .1 光热和化疗}

由于这类二维材料和石墨烯很类似，具有大的比表 面积, 因此它们可以用于装载输送一系列的药物分子. 我们课题组根据这一特性, 探索了单层 $\mathrm{MoS}_{2}$ 装载几种 模式药物的能力, 得到了的最高装载率为 $\mathrm{DOX}$ (约 239\%), Ce6(约 39\%)以及 SN38(约 118\%), 这与石墨烯的 装载能力相当. 在此基础上, 我们用端基为叶酸的聚乙 二醇修饰了的 $\mathrm{MoS}_{2}$ 为载体, 装载化疗模式药物 DOX, 实现了肿瘤细胞靶向的光热与化学药物的联合治疗. 随 后, 进一步将 $\mathrm{MoS}_{2}-\mathrm{PEG} / \mathrm{DOX}$ 通过肿瘤注射和尾静脉 注射进小鼠体内, 实现了活体水平上对肿瘤的光热与化 学药物联合治疗, 取得了很好的协同效果(图 6) ${ }^{[24 \mathrm{a}]}$. 国 家纳米科学中心赵宇亮课题组也通过壳聚糖修饰的 $\mathrm{MoS}_{2}$ 二维纳米材料装载 $\mathrm{DOX}$, 实现了光热与化疗的联 合, 有效地治疗了胰腺癌 ${ }^{[26]}$.

\section{2 .2 光热和光动力}

光动力治疗是通过激光照射光敏分子产生大量活 性氧自由基来杀伤肿瘤细胞的一种治疗方法. 由于大部 分的光敏分子不溶于水且不稳定, 肿瘤部位的氧含量也 较低，而活性氧自由基的有效作用时间和距离都较短， 因此单纯的光动力治疗很难完全消除肿瘤. 与此同时, 单纯的光热治疗需要很强的激光才能产生足够的高温 来消除肿瘤. 因此, 光热和光动力的联合提供了一种可 以消除各自治疗缺陷并提高抗癌效果的新治疗手段. 在 最近的工作中, 我们发现二维 $\mathrm{MoS}_{2}$ 纳米片状材料不仅 能够通过疏水作用力高效地装载不水溶的光敏分子 Ce6, 而且还能显著提高细胞对这种光敏分子的摄取能 
(a)
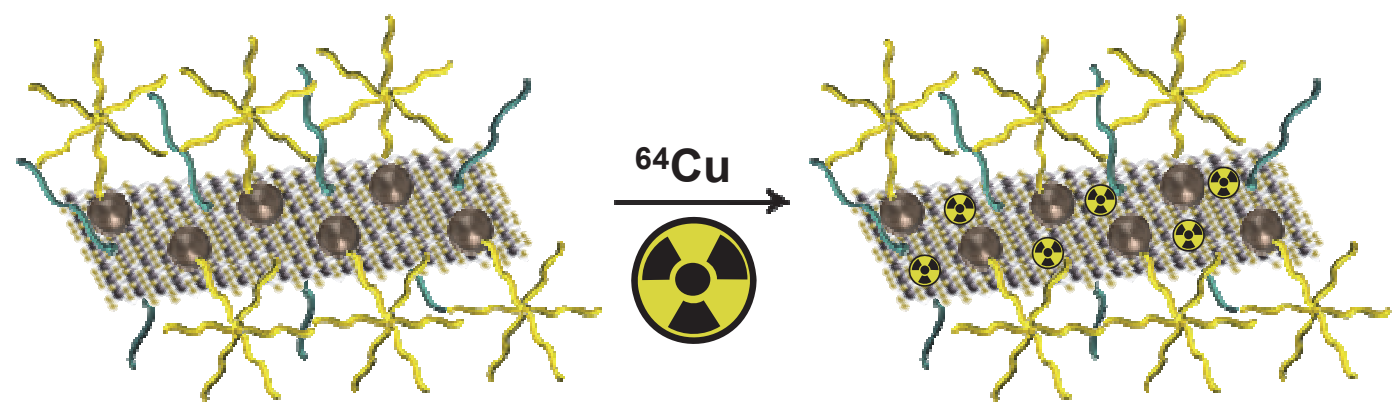

(b)

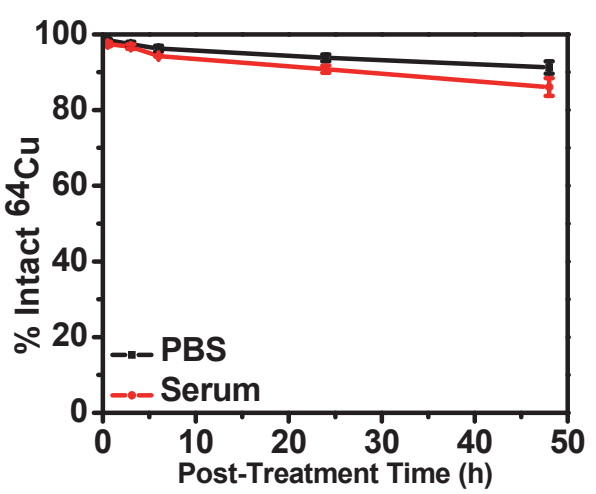

(d)

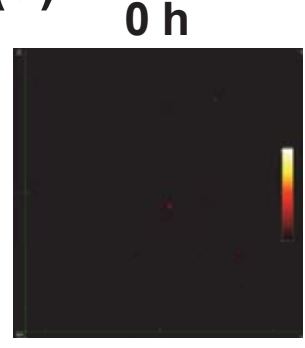

(c)

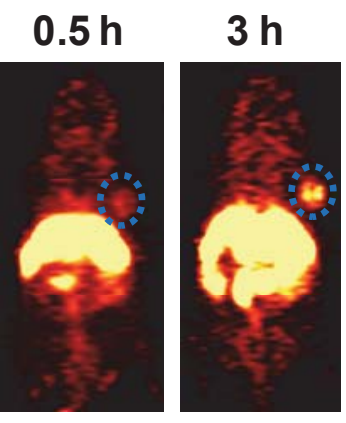

$6 \mathrm{~h}$

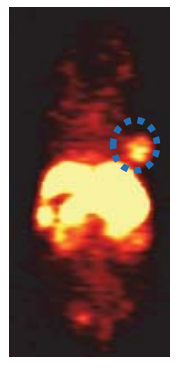

$8 \mathrm{~h}$

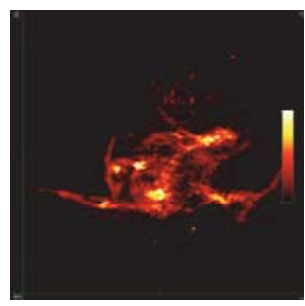

$24 \mathrm{~h} \quad 6 \%$ ID $/ g$

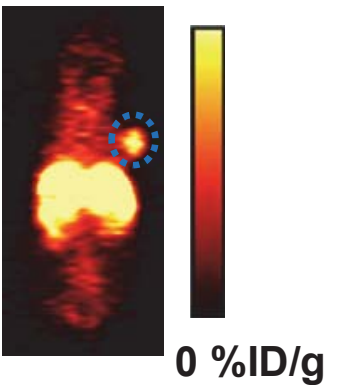

$24 \mathrm{~h}$

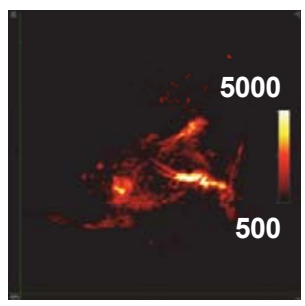

(e)
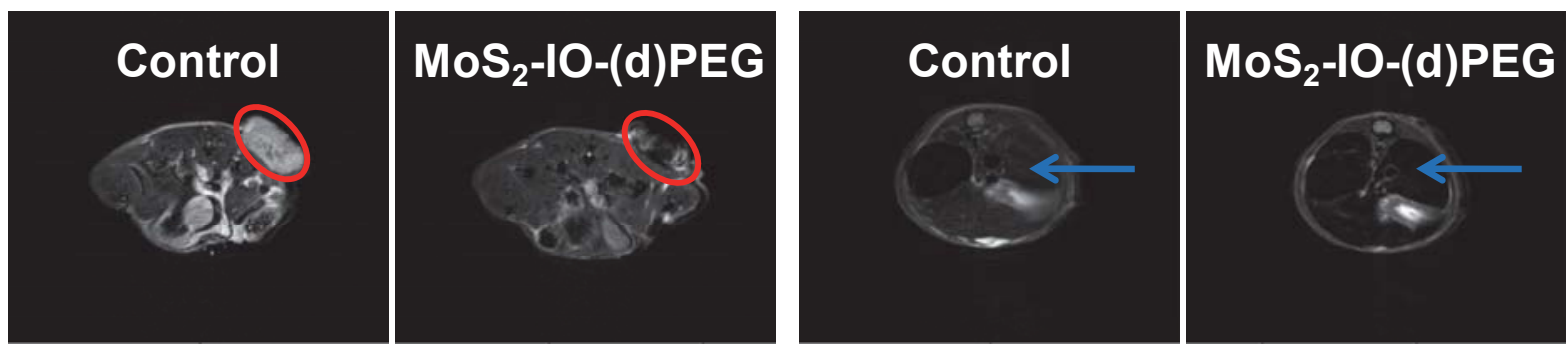

图 5 化学剥离法制得的 $\mathrm{MoS}_{2}$ 纳米片与配体结合的结构模型示意图. (a)无螯合剂的 ${ }^{64} \mathrm{Cu}$ 标记 $\mathrm{MoS}_{2}-\mathrm{IO}-(\mathrm{d}) \mathrm{PEG}$ 的示意图. (b)在不同时间点, ${ }^{64} \mathrm{Cu}$ 标记的 $\mathrm{MoS}_{2}-\mathrm{IO}-$-(d)PEG 在 PBS 和血清中的稳定性测试. (c)带4T1 肿瘤的小鼠在尾静脉注射 ${ }^{64} \mathrm{Cu}-\mathrm{MoS}_{2}-\mathrm{IO}-(\mathrm{d}) \mathrm{PEG}$ 后, 不同时间点的 PET成像图(蓝 色虚线圈标注了小鼠 4T1 肿瘤的位置). (d)尾静脉注射 ${ }^{64} \mathrm{Cu}-\mathrm{MoS}_{2}-\mathrm{IO}-(\mathrm{d}) \mathrm{PEG}\left(\mathrm{MoS}_{2}\right.$ 浓度为 $6.85 \mathrm{mg} / \mathrm{kg}$ ) 后, 不同时间点时小鼠 4T1 肿瘤的光声断 层扫描图像. (e)尾静脉注射 ${ }^{64} \mathrm{Cu}-\mathrm{MoS}_{2}-\mathrm{IO}-(\mathrm{d}) \mathrm{PEG}\left(\mathrm{MoS}_{2}\right.$ 浓度为 $6.85 \mathrm{mg} / \mathrm{kg}$ ) 后, T2 核磁成像的小鼠横向切面图(红色虚线圈和蓝色箭头分别标注 的是小鼠的肿瘤和肝部)

Figure 5 (a) Scheme presenting the ${ }^{64} \mathrm{Cu}$ labeling on $\mathrm{MoS}_{2}$-IO-(d)PEG via a chelator-free manner. (b) Stability test of ${ }^{64} \mathrm{Cu}$ labeling on $\mathrm{MoS}$-IO-(d)PEG after incubation in PBS and serum for different periods of time. (c) PET images of 4T1 tumor-bearing mice taken at various time points post i.v. injection of ${ }^{64} \mathrm{Cu}-\mathrm{MoS}_{2}$-IO-(d)PEG. The blue dot circles highlight the $4 \mathrm{~T} 1$ tumor site of mice. (d) PAT images of 4T1 tumor on mice acquired before and at various time points after i.v. injection with $\mathrm{MoS}_{2}-\mathrm{IO}$-(d)PEG (dose of $\mathrm{MoS}_{2}=6.85 \mathrm{mg} / \mathrm{kg}$ ). (e) T2-weighted MR images showing the transverse sections of a tumor-bearing mouse before and after injection with $\mathrm{MoS}_{2}-\mathrm{IO}-(\mathrm{d}) \mathrm{PEG}$ (dose of $\mathrm{MoS}_{2}=6.85 \mathrm{mg} / \mathrm{kg}$ ). The red circles and blue arrows highlight the $4 \mathrm{~T} 1$ tumor and liver of mice, respectively. Reprinted with permission from ref. [33]. Copyright 2015 American Chemical Society 
(a)

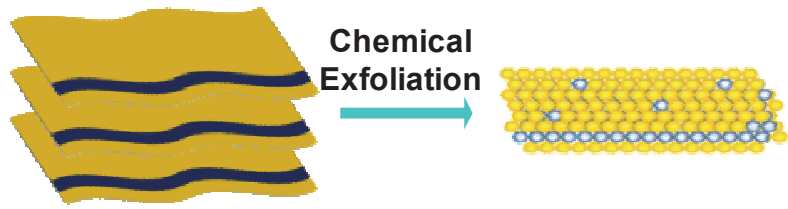

emical

s Drug molecules

Mo

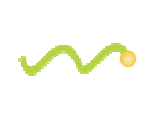

\section{LA-PEG}

LA-PEG

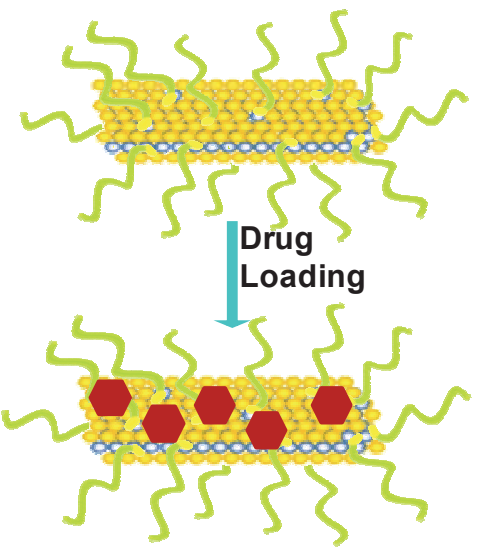

(d) (c)

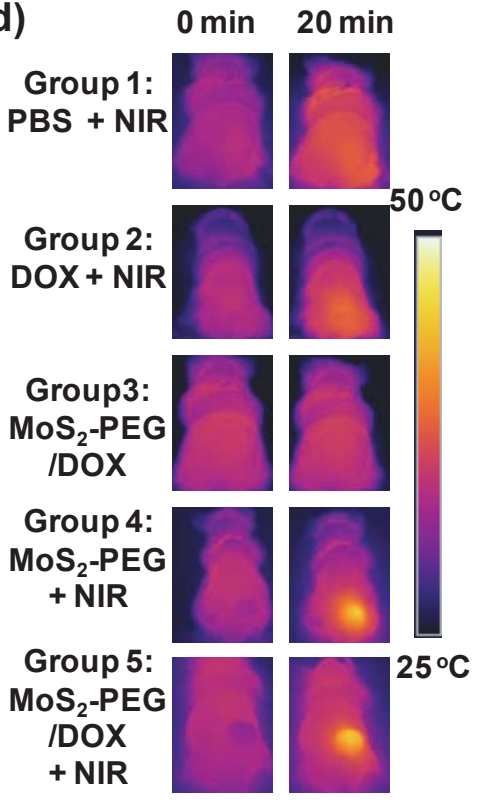

图 6 (a)制备 $\mathrm{MoS}_{2}$-PEG 和药物装载的示意图. (b)用 $\mathrm{MoS}_{2}-\mathrm{PEG}-\mathrm{FA} / \mathrm{DOX}$ 在细胞水平进行靶向联合治疗的示意图. (c)小鼠尾静脉注射 $\mathrm{MoS}_{2}-\mathrm{PEG} / \mathrm{DOX}$ 后进行联合治疗的示意图. (d)光热治疗时带 4T1 肿瘤小鼠的红外热成像图. DOX 和 $\mathrm{MoS}_{2}-\mathrm{PEG}$ 的浓度分别为 5 和 $3.4 \mathrm{mg} / \mathrm{kg}$. 使 用功率密度为 $0.56 \mathrm{~W} / \mathrm{cm}^{2}$ 的 $808 \mathrm{~nm}$ 激光对肿瘤照射了 $20 \mathrm{~min}$

Figure 6 (a) A scheme showing the fabrication process of $\mathrm{MoS}_{2}$-PEG and the subsequent drug loading. (b) A scheme showing in vitro targeted combination therapy with $\mathrm{MoS}_{2}$-PEG-FA/DOX. (c) Scheme of combination therapy based on intravenously injected $\mathrm{MoS}_{2}$-PEG/DOX. (d) IR thermal images of 4T1 tumor-bearing mice recorded by an IR camera. The doses of DOX and $\mathrm{MoS}_{2}-\mathrm{PEG}$ were 5 and $3.4 \mathrm{mg} / \mathrm{kg}$, respectively, in this experiment. Laser irradiation was conducted by using $808 \mathrm{~nm}$ NIR laser at the power density of $0.56 \mathrm{~W} / \mathrm{cm}^{2}$ for $20 \mathrm{~min}$ on the tumors. Reprinted with permission from ref. [24a]. Copyright 2014 Wiley-VCH

力, 从而大大增强活性距离较短的单线态氧对癌细胞的 杀伤力. 再考虑到 $\mathrm{MoS}_{2}$ 在近红外区的高吸收以及较高 的光热转化能力, 我们将 $\mathrm{MoS}_{2}-\mathrm{Ce} 6$ 纳米材料用于光热 与光动力的联合治疗. 我们发现低功率的激光照射 $\mathrm{MoS}_{2}-\mathrm{Ce} 6$ 产生的微量热, 能够进一步地有效促进细胞 吞噬材料, 从而大大提高了光动力治疗效果. 而在小鼠 活体上的联合治疗也显示了这种光热和光动力治疗的 协同效果 ${ }^{[24 b]}$. 而赵宇亮课题组 ${ }^{[27]}$ 则通过 $\mathrm{WS}_{2}$ 二维纳米 材料装载甲基蓝(MB), 通过 $\mathrm{WS}_{2}$ 的光热效应促进 $\mathrm{MB}$ 的 释放, 在 HeLa 细胞上实现了高效的光热和光动力的协 同治疗.

\section{TMDs 二维纳米材料的毒性初步研究}

纳米材料的生物安全性决定了它们是否能在临床 医学中取得真正的应用, 因此它们的毒性研究就尤其重 要. 最近的工作一些显示, 经过表面修饰的二维 TMDs 纳米材料即使在较高的浓度, 对多个细胞系都没有明显 的毒副作用.

而为了测试二维 TMDs 纳米材料在活体中的毒性, 我们课题组将修饰好的 $\mathrm{WS}_{2}$ 二维纳米材料 $(20 \mathrm{mg} / \mathrm{kg}$ ) 通 过系统性地尾静脉注射到小鼠体内, 并在接下来的 $45 \mathrm{~d}$ 中严密地观察小鼠的行为如体重、饮食、活性、排泄、 精神状态等，没有发现任何的异常，表明该材料没有明 

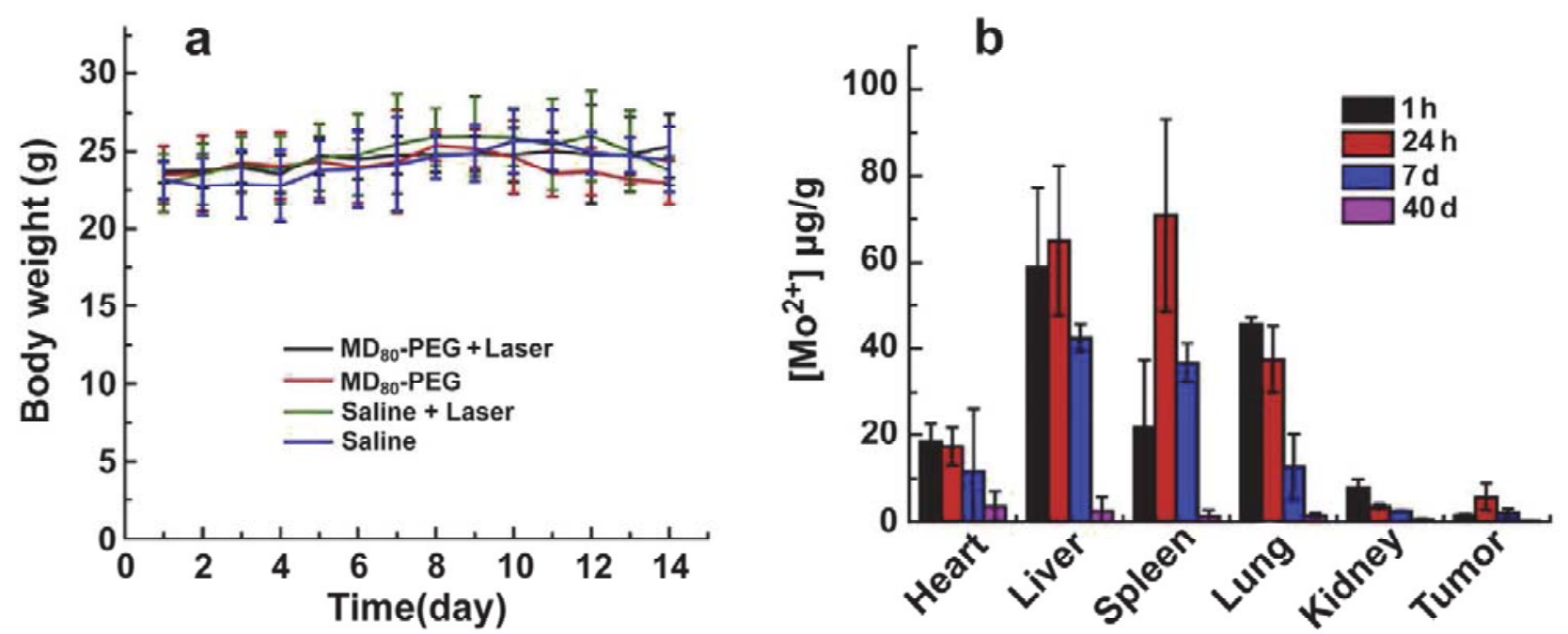

C Heart

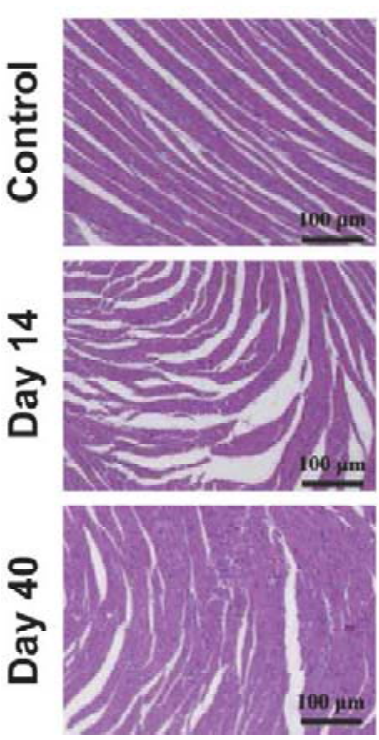

Liver
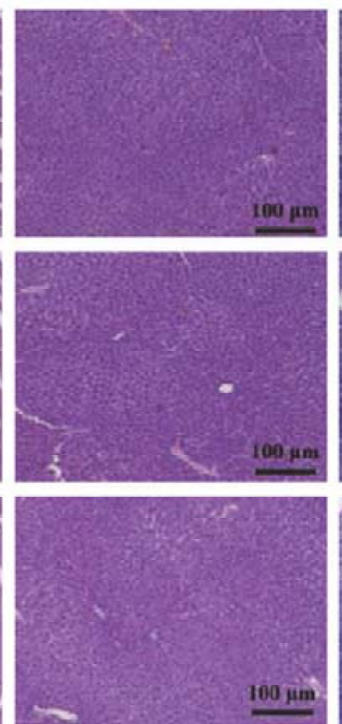

Spleen

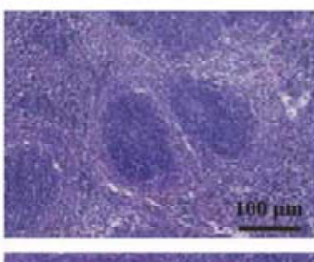

Lung

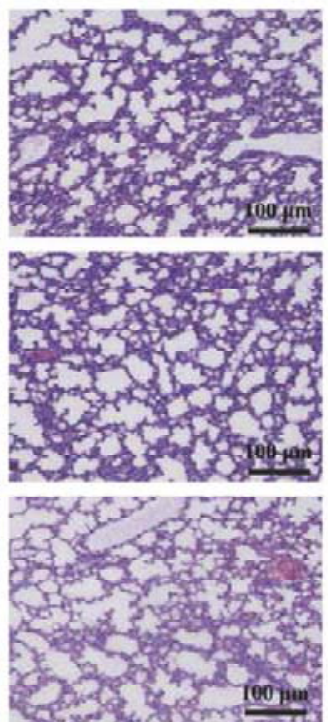

Kidney

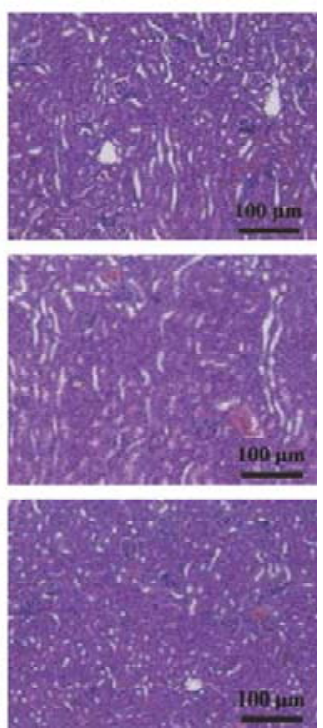

图 7 (a)带有 4T1 肿瘤的小鼠治疗后的体重变化(平均值土标准偏差, 一组 3 只). (b) 注射 MD80-PEG 后 Mo 元素在主要器官(心, 肝, 脾, 肺, 肾) 中不同时间的分布. (c) 注射 MD80-PEG 14 和 $18 \mathrm{~d}$ 后, 小鼠主要器官(心, 肝, 脾, 肺, 肾)经 H\&E 染色后的切片图(放大倍数: 100×)

Figure 7 (a) Body weight of 4T1 tumor-bearing mice after various treatments (mean $\pm \mathrm{SD}, n=3$ ). (b) Biodistribution of Mo in major organs, including the heart, liver, spleen, lung, and kidney, and tumor at different time points post-treatment with MD80-PEG (mean $\pm \mathrm{SD}, n=3$ ). (c) H\&E-stained tissue sections of major organs, including the heart, liver, spleen, lung, and kidney from mice treated with saline (control) or MD80-PEG at day 14 and day 40 (magnification: $100 \times$ ). Reprinted with permission from ref. [19a]. Copyright 2014 Elsevier Ltd

显的毒副作用. 随后, 我们对牺牲的小鼠的器官切片染 色后进行组织学分析, 没有发现任何器官损伤和炎症病 变. 在血清生物化学分析和全血分析中, 我们发现所有 的参数都在正常范围之内, 进一步证明了 $\mathrm{WS}_{2}$ 二维纳米 材料在我们的测试浓度上没有明显的毒性 ${ }^{[23]}$. 类似地, 中国科学院上海硅酸盐研究所的施剑林等通过长期监 测材料的生物分布, 并观察染色的组织切片, 发现 $\mathrm{MoS}_{2}$ 二维纳米材料会随着时间逐渐代谢, $40 \mathrm{~d}$ 后几乎在 主要器官消失, 证实了它们在小鼠体内的生物安全 性 ${ }^{[19 a, 24 a]}$. 值得注意的是, TMDs 二维纳米材料的组成元 素、尺寸大小、表面修饰等对它们生物安全性有很大的 的影响, 因此需要更全面深入的的毒性研究.

\section{6 结论和展望}

近年来, 二维 TMDs 纳米材料发展迅速, 本文简单 介绍了它们在医学领域的最新进展. 一些课题组开始将 二维 TMDs 纳米材料应用于生物检测、生物成像、光热 治疗、药物装载等诸多方向. 但是与石墨烯相比, 二维 TMDs 纳米材料的研究还处于初级阶段, 生物医学领域 的探索更是方兴未艾, 还有很多重要的问题需要我们研 究解决.

首先, 我们需要优化合成方法, 快速、便捷、廉价、 高效地制备不同种类，尺寸均一的二维 TMDs 纳米材 料，并通过完善的表面修饰使其拥有很好的生物相容 
性. 其次, 我们需要进一步开发 TMDs 与其他功能纳米 材料的组装来实现多功能化, 我们也可以尝试通过在合 成过程中掺杂其他元素(如 Fe, Mn, Co, Ni)来丰富 TMDs 的性质与功能. 再则, 它们在生物医学领域的应用还有 待开发, 如基因治疗、组织工程等. 最后, 为了实现二维 TMDs 纳米材料在临床医学上真正的应用, 我们还要深 入全面地研究不同 TMDs 材料在生物体内的分布、长期 毒性和代谢情况，以及 TMDs 的合成方法、组成元素、 尺寸大小、表面修饰等对它们生物安全性的影响.

考虑到二维 TMDs 纳米材料较短的研究时间和如 此迅猛的发展速度, 我们有理由相信, 通过不同领域的 研究者之间紧密的合作, 这种性质丰富的纳米材料可以 在不久的将来在纳米生物医药中取得广泛的发展和应 用。

\section{作者简介}

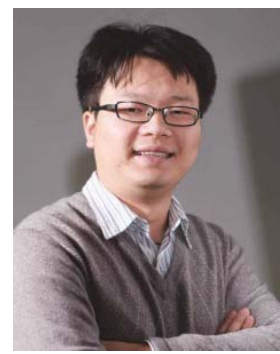

刘庄, 苏州大学教授. 2004 年北京大学化学与分子工程学 院获学士学位; 2008 年美国斯坦福大学获得化学博士学位; 2009 年 6 月加入苏州大学功能纳米与软物质研究院. 近年来 在纳米生物医学材料与肿瘤纳米技术领域从事研究. 共发表 学术论文 140 余篇, 论文总他引超过 14000 次(SCI H-index $=$ 57). 获自然科学基金委优秀青年基金和江苏省杰出青年基金 资助. 获得奖励包括 MRS Silver Award、SCOPUS 青年科学之 星银奖、中国化学会青年化学奖等。担任学术期刊 Biomaterials 杂志 Associate Editor, Scientific Reports (NPG)、 Nano Research 等多个期刊编委.

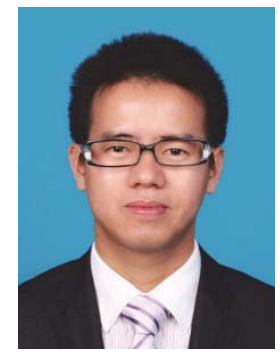

程亮, 苏州大学副教授. 2006 年和 2009 年在安徽工程大 学和安徽师范大学分别获得应用化学学士学位和无机化学硕 士学位; 2012 年 6 月, 苏州大学功能纳米与软物质研究院获得 应用化学博士学位; 2012 年 8 月开始担任苏州大学功能纳米与 软物质研究院讲师; 2014 年 7 月破格晋升为苏州大学功能纳米 与软物质研究院副教授. 目前的研究方向主要集中在功能性 复合纳米材料在生物医学成像、药物输送和癌症综合治疗等 方面的应用.

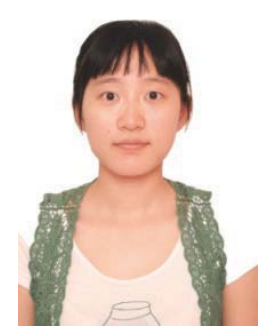

刘腾, 2012 年在苏州大学材料与化学化工学部获得化学 学士学位, 之后进入苏州大学功能纳米与软物质研究院开始 攻读博士学位. 研究方向主要集中在二维过渡金属硫族化合 物及其衍生物在生物医学中的应用.

\section{References}

[1] (a) Zhang, X.; Xie, Y. Chem. Soc. Rev. 2013, 42, 8187. (b) Novoselov, K.; Geim, A. K.; Morozov, S.; Jiang, D.; Katsnelson, M.; Grigorieva, I.; Dubonos, S.; Firsov, A. Nature 2005, 438, 197. (c) Sun, Y.; Gao, S.; Lei, F.; Xiao, C.; Xie, Y. Acc. Chem. Res. 2015, 48 3. (d) Lin, Y. W.; Guo, X. F. Acta Chim. Sinica 2013, 72, 277. (林源 为, 郭雪峰, 化学学报, 2013, 72, 277.)

[2] Lui, C. H.; Liu, L.; Mak, K. F.; Flynn, G. W.; Heinz, T. F. Nature 2009, 462, 339.

[3] (a) Novoselov, K. S.; Geim, A. K.; Morozov, S.; Jiang, D.; Zhang, Y.; Dubonos, S.; Grigorieva, I.; Firsov, A. Science 2004, 306, 666. (b) Yang, K.; Zhang, S.; Zhang, G.; Sun, X.; Lee, S.-T.; Liu, Z. Nano Lett. 2010, 10, 3318. (c) Huang, X.; Yin, Z.; Wu, S.; Qi, X.; He, Q.; Zhang, Q.; Yan, Q.; Boey, F.; Zhang, H. Small 2011, 7, 1876. (d) Geim, A. K. Science 2009, 324, 1530.

[4] Butler, S. Z.; Hollen, S. M.; Cao, L.; Cui, Y.; Gupta, J. A.; Gutierrez, H. R.; Heinz, T. F.; Hong, S. S.; Huang, J.; Ismach, A. F. ACS Nano 2013, 7, 2898.

[5] Huang, X.; Zeng, Z.; Zhang, H. Chem. Soc. Rev. 2013, 42, 1934.

[6] Radisavljevic, B.; Radenovic, A.; Brivio, J.; Giacometti, V.; Kis, A. Nat. Nanotechnol. 2011, 6, 147.

[7] (a) Xiao, J.; Choi, D.; Cosimbescu, L.; Koech, P.; Liu, J.; Lemmon, J. P. Chem. Mater. 2010, 22, 4522. (b) Hwang, H.; Kim, H.; Cho, J. Nano Lett. 2011, 11, 4826.

[8] Radisavljevic, B.; Whitwick, M. B.; Kis, A. ACS Nano 2011, 5, 9934.

[9] (a) Li, H.; Yin, Z.; He, Q.; Li, H.; Huang, X.; Lu, G.; Fam, D. W. H.; Tok, A. I. Y.; Zhang, Q.; Zhang, H. Small 2012, 8, 63. (b) Yang, J.; Voiry, D.; Ahn, S. J.; Kang, D.; Kim, A. Y.; Chhowalla, M.; Shin, H. S. Angew. Chem., Int. Ed. 2013, 52, 13751.

[10] Jaramillo, T. F.; Jørgensen, K. P.; Bonde, J.; Nielsen, J. H.; Horch, S.; Chorkendorff, I. Science 2007, 317, 100.

[11] (a) Yin, Z.; Li, H.; Li, H.; Jiang, L.; Shi, Y.; Sun, Y.; Lu, G.; Zhang, Q.; Chen, X.; Zhang, H. ACS Nano 2011, 6, 74. (b) Perea - López, N.; Elías, A. L.; Berkdemir, A.; Castro-Beltran, A.; Gutiérrez, H. R.; Feng, S.; Lv, R.; Hayashi, T.; López-Urí as, F.; Ghosh, S. Adv. Funct. Mater. 2013, 23, 5511. (c) Wang, Q. H.; Kalantar-Zadeh, K.; Kis, A.; Coleman, J. N.; Strano, M. S. Nat. Nanotechnol. 2012, 7, 699.

[12] Chianelli, R. R.; Siadati, M. H.; De la Rosa, M. P.; Berhault, G.; Wilcoxon, J. P.; Bearden Jr, R.; Abrams, B. L. Catal. Rev. 2006, 48, 1

[13] Chen, Y.; Tan, C.; Zhang, H.; Wang, L. Chem. Soc. Rev. 2015, 44, 2681

[14] Novoselov, K.; Jiang, D.; Schedin, F.; Booth, T.; Khotkevich, V.; Morozov, S.; Geim, A. Proc. Natl. Acad. Sci. U. S. A. 2005, 102, 10451 .

[15] (a) Coleman, J. N.; Lotya, M.; O’Neill, A.; Bergin, S. D.; King, P. J.; Khan, U.; Young, K.; Gaucher, A.; De, S.; Smith, R. J. Science 2011, 331, 568. (b) Cunningham, G.; Lotya, M.; Cucinotta, C. S.; Sanvito, S.; Bergin, S. D.; Menzel, R.; Shaffer, M. S.; Coleman, J. N. ACS Nano 2012, 6, 3468. (c) Zhou, K. G.; Mao, N. N.; Wang, H. X.; Peng, Y.; Zhang, H. L. Angew. Chem., Int. Ed. 2011, 50, 10839. (d) Nicolosi, V.; Chhowalla, M.; Kanatzidis, M. G.; Strano, M. S.; Coleman, J. N. Science 2013, 340, 1226419.

[16] Joensen, P.; Frindt, R.; Morrison, S. R. Mater. Res. Bull. 1986, 21, 
457.

[17] (a) Zeng, Z.; Sun, T.; Zhu, J.; Huang, X.; Yin, Z.; Lu, G.; Fan, Z.; Yan, Q.; Hng, H. H.; Zhang, H. Angew. Chem., Int. Ed. 2012, 51, 9052; (b) Zeng, Z.; Yin, Z.; Huang, X.; Li, H.; He, Q.; Lu, G.; Boey, F.; Zhang, H. Angew. Chem., Int. Ed. 2011, 50, 11093.

[18] (a) Liu, K.-K.; Zhang, W.; Lee, Y.-H.; Lin, Y.-C.; Chang, M.-T.; Su, C.-Y.; Chang, C.-S.; Li, H.; Shi, Y.; Zhang, H. Nano Lett. 2012, 12, 1538. (b) Lee, Y. H.; Zhang, X. Q.; Zhang, W.; Chang, M. T.; Lin, C. T.; Chang, K. D.; Yu, Y. C.; Wang, J. T. W.; Chang, C. S.; Li, L. J. Adv. Mater. 2012, 24, 2320. (c) Najmaei, S.; Liu, Z.; Zhou, W.; Zou, X.; Shi, G.; Lei, S.; Yakobson, B. I.; Idrobo, J.-C.; Ajayan, P. M.; Lou, J. Nat. Mater. 2013, 12, 754. (d) Wang, X.; Feng, H.; Wu, Y.; Jiao, L. J. Am. Chem. Soc. 2013, 135, 5304. (e) Zhang, Y.; Zhang, Y.; Ji, Q.; Ju, J.; Yuan, H.; Shi, J.; Gao, T.; Ma, D.; Liu, M.; Chen, Y. ACS Nano 2013, 7, 8963.

[19] (a) Wang, S.; Li, K.; Chen, Y.; Chen, H.; Ma, M.; Feng, J.; Zhao, Q.; Shi, J. Biomaterials 2015, 39, 206. (b) Chen, G.; Yu, Y.; Zheng, K.; Ding, T.; Wang, W.; Jiang, Y.; Yang, Q. Small 2015, 11, 2847. (c) Wang, S.; Li, X.; Chen, Y.; Cai, X.; Yao, H.; Gao, W.; Zheng, Y.; An, X.; Shi, J.; Chen, H. Adv. Mater. 2015, 27, 2775.

[20] (a) Min, Y.; Moon, G. D.; Kim, B. S.; Lim, B.; Kim, J.-S.; Kang, C. Y.; Jeong, U. J. Am. Chem. Soc. 2012, 134, 2872. (b) Cheng, L.; Huang, W.; Gong, Q.; Liu, C.; Liu, Z.; Li, Y.; Dai, H. Angew. Chem., Int. Ed. 2014, 53, 7860. (c) Qian, X.; Shen, S.; Liu, T.; Cheng, L.; Liu, Z. Nanoscale 2015, 7, 6380. (d) Gong, Q.; Cheng, L.; Liu, C.; Zhang, M.; Feng, Q.; Ye, H.; Zeng, M.; Xie, L.; Liu, Z.; Li, Y. ACS Catal. 2015, 5, 2213.

[21] Xu, G.; Lu, Z.; Zhang, Q.; Qiu, H.; Jiao, L. Acta Chim. Sinica 2015 , 73, 895. (许冠辰, 卢至行, 张琪, 邱海龙, 焦丽颖, 化学学报, 2015, 73, 895.)
[22] Chou, S. S.; De, M.; Kim, J.; Byun, S.; Dykstra, C.; Yu, J.; Huang, J.; Dravid, V. P. J. Am. Chem. Soc. 2013, 135, 4584.

[23] Cheng, L.; Liu, J.; Gu, X.; Gong, H.; Shi, X.; Liu, T.; Wang, C.; Wang, X.; Liu, G.; Xing, H. Adv. Mater. 2014, 26, 1886.

[24] (a) Liu, T.; Wang, C.; Gu, X.; Gong, H.; Cheng, L.; Shi, X.; Feng, L.; Sun, B.; Liu, Z. Adv. Mater. 2014, 26, 3433. (b) Liu, T.; Wang, C.; Cui, W.; Gong, H.; Liang, C.; Shi, X.; Li, Z.; Sun, B.; Liu, Z. Nanoscale 2014, 6, 11219.

[25] Yuan, Y.; Li, R.; Liu, Z. Anal. Chem. 2014, 86, 3610.

[26] Yin, W.; Yan, L.; Yu, J.; Tian, G.; Zhou, L.; Zheng, X.; Zhang, X.; Yong, Y.; Li, J.; Gu, Z. ACS Nano 2014, 8, 6922.

[27] Yong, Y.; Zhou, L.; Gu, Z.; Yan, L.; Tian, G.; Zheng, X.; Liu, X.; Zhang, X.; Shi, J.; Cong, W. Nanoscale 2014, 6, 10394.

[28] Zhu, C.; Zeng, Z.; Li, H.; Li, F.; Fan, C.; Zhang, H. J. Am. Chem. Soc. 2013, 135, 5998 .

[29] Ou, J. Z.; Chrimes, A. F.; Wang, Y.; Tang, S.-y.; Strano, M. S.; Kalantar-zadeh, K. Nano Lett. 2014, 14, 857.

[30] Sarkar, D.; Liu, W.; Xie, X.; Anselmo, A. C.; Mitragotri, S.; Banerjee, K. ACS Nano 2014, 8, 3992.

[31] Xi, Q.; Zhou, D.-M.; Kan, Y.-Y.; Ge, J.; Wu, Z.-K.; Yu, R.-Q.; Jiang, J.-H. Anal. Chem. 2014, 86, 1361.

[32] Wang, L. V.; Hu, S. Science 2012, 335, 1458.

[33] Liu, T.; Shi, S.; Liang, C.; Shen, S.; Cheng, L.; Wang, C.; Song, X.; Goel, S.; Barnhart, T. E.; Cai, W. ACS Nano 2015, 9, 950.

[34] Chou, S. S.; Kaehr, B.; Kim, J.; Foley, B. M.; De, M.; Hopkins, P. E.; Huang, J.; Brinker, C. J.; Dravid, V. P. Angew. Chem. 2013, 125 4254 .

(Qin, X.) 